\title{
Video Article \\ Identification of Enhancer-Promoter Contacts in Embryoid Bodies by Quantitative Chromosome Conformation Capture (4C)
}

\author{
Tian V. $\operatorname{Tian}^{1,2,3}$, Enrique Vidal ${ }^{1,2}$, Thomas Graf ${ }^{1,2}$, Grégoire Stik ${ }^{1,2}$ \\ ${ }^{1}$ Center for Genomic Regulation (CRG), The Barcelona Institute of Science and Technology \\ 2 Universitat Pompeu Fabra \\ ${ }^{3}$ Vall d'Hebron Institute of Oncology
}

Correspondence to: Tian V. Tian at tiantian@vhio.net, Thomas Graf at thomas.graf@crg.eu, Grégoire Stik at gregoire.stik@crg.eu

URL: https://www.jove.com/video/60960

DOI: doi:10.3791/60960

Keywords: Genetics, Issue 158, development, transcription regulation, embryoid body, lineage specification, enhancer, promoter, chromosome conformation capture, $4 \mathrm{C}$

Date Published: 4/29/2020

Citation: Tian, T.V., Vidal, E., Graf, T., Stik, G. Identification of Enhancer-Promoter Contacts in Embryoid Bodies by Quantitative Chromosome Conformation Capture (4C). J. Vis. Exp. (158), e60960, doi:10.3791/60960 (2020).

\section{Abstract}

During mammalian development, cell fates are determined through the establishment of regulatory networks that define the specificity, timing and spatial patterns of gene expression. Embryoid bodies (EBs) derived from pluripotent stem cells have been a popular model to study the differentiation of the main three germ layers and to define regulatory circuits during cell fate specification. Although it is well-known that tissuespecific enhancers play an important role in these networks by interacting with promoters, assigning them to their relevant target genes still remains challenging. To make this possible, quantitative approaches are needed to study enhancer-promoter contacts and their dynamics during development. Here, we adapted a 4C method to define enhancers and their contacts with cognate promoters in the EB differentiation model. The method uses frequently cutting restriction enzymes, sonication, and a nested-ligation-mediated PCR protocol compatible with commercial DNA library preparation kits. Subsequently, the $4 \mathrm{C}$ libraries are subjected to high-throughput sequencing and analyzed bioinformatically, allowing detection and quantification of all sequences that have contacts with a chosen promoter. The resulting sequencing data can also be used to gain information about the dynamics of enhancer-promoter contacts during differentiation. The technique described for the EB differentiation model is easy to implement.

\section{Video Link}

The video component of this article can be found at https://www.jove.com/video/60960/

\section{Introduction}

In mice, the inner cell mass (ICM) of 3.5-day-old embryos contains embryonic pluripotent stem cells. The ICM further develops into the epiblast at day 4.5, generating ectoderm, mesoderm, and endoderm cells, the main three germ layers in the embryo. Although pluripotent cells in the ICM exist only transiently in vivo, they can be captured in culture by the establishment of mouse embryonic stem cells (mESCs) ${ }^{1,2,3}$. The mESCs remain in an undifferentiated state and proliferate indefinitely, yet upon intrinsic and extrinsic stimuli they are also capable of exiting the pluripotency state and generating cells of the three developmental germ layers ${ }^{2,4}$. Interestingly, when cultured in suspension in small droplets, mESCs form three-dimensional aggregates (i.e., EBs) that differentiate into all three germ layers ${ }^{5}$. The EB formation assay is an important tool to study the early lineage specification process.

During lineage specification, cells of each germ layer acquire a specific gene expression program ${ }^{4}$. The precise spatiotemporal expression of genes is regulated by diverse cis-regulatory elements, including core promoters, enhancers, silencers, and insulators ${ }^{6,7,8,9}$. Enhancers, regulatory DNA segments typically spanning a few hundred base pairs, coordinate tissue-specific gene expression ${ }^{8}$. Enhancers are activated or silenced by binding of transcription factors and cofactors that regulate local chromatin structure ${ }^{8,10}$. Commonly used techniques to identify putative enhancers are genome-wide chromatin immunoprecipitation followed by sequencing (ChIP-seq) and the assay for transposaseaccessible chromatin using sequencing (ATAC-seq) techniques. Thus, active enhancers are characterized by specific active histone marks and by increased local DNA accessibility ${ }^{11,12,13,14}$. In addition, developmental enhancers are believed to require physical interaction with their cognate promoter $^{8,9}$. Indeed, it has been shown that enhancer variants and deletions that disrupt enhancer-promoter contacts can lead to developmental malformations ${ }^{15}$. Therefore, there is a need for novel techniques that provide additional information for the identification of functional enhancers that control developmental gene expression.

Since the development of the chromosome conformation capture $(3 \mathrm{C})$ technique ${ }^{16}$, the mapping of chromosomal contacts has been intensively used to assess physical distance between regulatory elements. Importantly, high-throughput variants of $3 \mathrm{C}$ techniques have recently been developed, providing different strategies for fixation, digestion, ligation, and recovery of contacts between chromatin fragments ${ }^{17}$. Among them, in situ $\mathrm{Hi}-\mathrm{C}$ has become a popular technique allowing the sequencing of $3 \mathrm{C}$ ligation products genome-wide ${ }^{18}$. However, the high sequencing costs required to reach a resolution suitable for the analysis of enhancer-promoter contacts makes this technique impractical for the study of specific loci. Therefore, alternative methods were developed to analyze targeted loci at higher resolution ${ }^{19,20,21,22}$. One of these methods, namely 
4C, known as a one versus all strategy, allows detection of all sequences that contact a site selected as viewpoint. However, a disadvantage of the standard $4 \mathrm{C}$ technique is the inverse PCR required, which amplifies differently sized fragments, favoring small products and biasing quantification after high-throughput sequencing. Recently, UMI-4C, a new variant of the $4 \mathrm{C}$ technique using unique molecular identifiers (UMI) has been developed for quantitative and targeted chromosomal contact profiling that circumvents this problem ${ }^{23}$. This approach uses frequent cutters, sonication, and a nested-ligation-mediated PCR protocol, thereby involving amplification of DNA fragments with relatively uniform length distribution. This homogeneity reduces biases in the amplification process of PCR preferences for shorter sequences and allows efficient recovery and accurate counting of spatially connected molecules/fragments.

Here we describe a protocol that adapts the UMI-4C technique to identify and quantify chromatin contacts between promoters and enhancers of lineage instructive transcription factors during EB differentiation.

\section{Embryoid body generation from mouse embryonic stem cells}

1. Prepare $\mathrm{mESC}$ serum-free culture medium: DMEM/F12 and neurobasal medium mixed at a ratio of $1: 1$. The culture medium is supplemented with MEM non-essential amino acids solution (1x), sodium pyruvate $(1 \mathrm{mM})$, L-glutamine $(2 \mathrm{mM})$, penicillin-streptomycin $(100 \mathrm{U} / \mathrm{mL})$, beta-

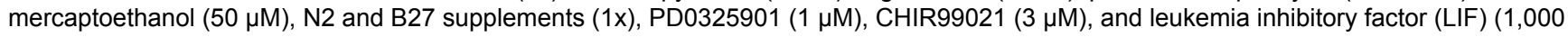
$\mathrm{U} / \mathrm{mL})$.

2. Prepare EB differentiation medium: DMEM supplemented with $10 \%$ fetal bovine serum (FBS), MEM non-essential amino acids (1x), sodium pyruvate $(1 \mathrm{mM})$, L-glutamine $(2 \mathrm{mM})$, penicillin-streptomycin $(100 \mathrm{U} / \mathrm{mL})$, beta-mercaptoethanol $(50 \mu \mathrm{M})$.

3. Culture $\mathrm{mESCs}$ on $10 \mathrm{~cm}$ plastic dishes precoated with $0.1 \%(\mathrm{w} / \mathrm{v})$ gelatin in $\mathrm{mESC}$ culture serum-free medium.

4. When $\mathrm{mESC}$ reach $60 \%$ confluency, remove culture medium and wash gently $1 \mathrm{x}$ with $2 \mathrm{~mL}$ of sterilized PBS.

5. Remove PBS completely and add $2 \mathrm{~mL}$ of cell detachment medium. Incubate the culture dish at $37^{\circ} \mathrm{C}$ for $5 \mathrm{~min}$.

6. Inactivate the reaction by adding $8 \mathrm{~mL}$ of EB differentiation medium into the dish.

7. Dissociate $\mathrm{mESC}$ colonies by pipetting up and down 15-20 times to obtain a single-cell suspension.

8. Centrifuge the cells at $300 \times g$ at room temperature (RT) for 5 min and carefully remove the supernatant.

9. Count cells (e.g., using a hemocytometer).

10. Resuspend the cell pellet with EB differentiation medium and adjust the concentration to $2 \times 10^{4}$ cells $/ \mathrm{mL}$.

11. Invert the lid of a $15 \mathrm{~cm}$ culture dish and use a $200 \mu \mathrm{L}$ multichannel pipette to deposit $20 \mu \mathrm{L}$ drops of resuspended cells ( 400 cells/drop) on the lid.

12. Invert the lid carefully onto the bottom chamber and incubate the dish with hanging drops at $37{ }^{\circ} \mathrm{C}$ with $5 \% \mathrm{CO}_{2}$ and $95 \%$ humidity for 3 days.

13. Collect the EBs by washing the lid gently with $10 \mathrm{~mL}$ of PBS and transfer the EB-containing suspension to a $50 \mathrm{~mL}$ plastic tube.

14. Place the tube at RT for $30 \mathrm{~min}$, so that the EBs will sink to the bottom by gravity. Carefully remove the supernatant.

15. Resuspend the EBs gently with $10 \mathrm{~mL}$ of fresh EB differentiation medium and transfer to a $10 \mathrm{~cm}$ bacteriological Petri dish.

16. Check EB formation 3-6 days later using an inverted microscope. The EBs generated should be round and homogeneous in size.

17. Incubate the cultures at $37^{\circ} \mathrm{C}$ with $5 \% \mathrm{CO}_{2}$ and $95 \%$ humidity. EBs will continue to differentiate into the three germ layers and can be collected at various timepoints for analysis.

\section{Dissociation of EBs}

1. Collect the EBs from two to three $10 \mathrm{~cm}$ dishes into a $50 \mathrm{~mL}$ plastic tube. Centrifuge the EBs at $300 \times g$ at RT for 5 min, then carefully remove the supernatant.

2. Resuspend the EBs with $10 \mathrm{~mL}$ of PBS. Centrifuge EBs at $300 \times g$ at RT for $3 \mathrm{~min}$ and remove the supernatant.

3. Add $2 \mathrm{~mL}$ of trypsin-EDTA (0.25\%) to the pellet and incubate the tube at $37^{\circ} \mathrm{C}$ for $15 \mathrm{~min}$. Pipette up and down every $3 \mathrm{~min}$ to obtain a singlecell suspension.

4. Add $8 \mathrm{~mL}$ of EB differentiation medium to stop the trypsin reaction. Check EB dissociation under the microscope and count the cells.

\section{Fixation}

1. Resuspend the cells in fresh EB culture medium at $1 \times 10^{6}$ cells $/ \mathrm{mL}$. For a $50 \mathrm{~mL}$ tube, use a maximum of $4.5 \times 10^{7}$ cells in $45 \mathrm{~mL}$ of medium.

2. Add paraformaldehyde from a $37 \%$ stock (not older than 6 months) to a $1 \%$ final concentration.

CAUTION: Follow appropriate health and safety regulations while handling paraformaldehyde because it is a hazardous chemical.

3. Incubate for $10 \mathrm{~min}$ at RT under rotation.

4. Quench the formaldehyde by adding glycine to a final concentration of $0.125 \mathrm{M}$.

5. Incubate for 5 min at RT under rotation.

6. Transfer the fixed cells to ice and keep cold at $4{ }^{\circ} \mathrm{C}$ from now on.

7. Pellet the cells at $300 \times g$ for 5 min in a refrigerated centrifuge.

8. Discard the supernatant and resuspend the pellet in cold PBS ( $1 \mathrm{~mL}$ for $5 \times 10^{6}$ cells), then transfer to $1.5 \mathrm{~mL}$ safe-lock tubes.

9. Pellet the cells at $300 \times \mathrm{g}$ for $5 \mathrm{~min}$ at $4{ }^{\circ} \mathrm{C}$, discard the supernatant, and snap-freeze the pellets in liquid nitrogen. Store at $-80{ }^{\circ} \mathrm{C}$ or proceed with the protocol below.

\section{Cell lysis and restriction enzyme digest}

1. Gently resuspend the cell pellet in $0.25 \mathrm{~mL}$ of freshly prepared ice-cold lysis buffer $(10 \mathrm{mM}$ Tris- $\mathrm{HCl} \mathrm{pH}=8.0,10 \mathrm{mM} \mathrm{NaCl}, 0.2 \%$ Igepal CA630, and $1 \times$ protease inhibitors) per $2-5 \times 10^{6}$ cells. To prepare $5 \mathrm{~mL}$ of lysis buffer, see Table 1. 
2. Incubate the cells for 15 min on ice.

3. Centrifuge at $1,000 \times g$ for $5 \mathrm{~min}$ at $4{ }^{\circ} \mathrm{C}$. Discard the supernatant and keep the pellet, which contains the nuclei.

4. Wash the pelleted nuclei with $500 \mu \mathrm{L}$ of cold lysis buffer.

5. Gently resuspend the pellet in a $1.5 \mathrm{~mL}$ tube with $50 \mu \mathrm{L}$ of $0.5 \%$ SDS in $1 \mathrm{x}$ buffer 2 , then incubate the tube in a heating block at $62{ }^{\circ} \mathrm{C}$ for 10 $\min$.

6. Remove the tubes from the heating block and add $170 \mu \mathrm{L}$ of digestion buffer containing $25 \mu \mathrm{L}$ of $10 \%$ triton $\mathrm{X}-100$ to quench the SDS. Mix well by pipetting, avoiding excessive foaming.

7. Incubate at $37^{\circ} \mathrm{C}$ for $15 \mathrm{~min}$.

8. Add $25 \mu \mathrm{L}$ of digestion buffer, mix by inverting, and take $8 \mu \mathrm{L}$ as an undigested control. Keep the undigested control sample at $-20{ }^{\circ} \mathrm{C}$. Add $100 \mathrm{U} \mathrm{Mbol}$ restriction enzyme $\left(4 \mu \mathrm{L}\right.$ of a $25 \mathrm{U} / \mu \mathrm{L}$ stock) to the remaining nuclei and digest the chromatin for $2 \mathrm{~h}$ at $37^{\circ} \mathrm{C}$ under rotation. Add another aliquot of $100 \mathrm{U}$ of $\mathrm{Mbol}$ and incubate for an additional $2 \mathrm{~h}$.

9. Add another $100 \mathrm{U}$ of $\mathrm{Mbol}$ and incubate under rotation overnight at $37^{\circ} \mathrm{C}$.

10. The next day, add another $100 \mathrm{U}$ of $\mathrm{Mbol}$ and incubate for $3 \mathrm{~h}$ at $37^{\circ} \mathrm{C}$ under rotation.

11. Take $8 \mu \mathrm{L}$ as a digested control sample. De-crosslink digested control samples and the undigested control samples from step 4.8 by adding $80 \mu \mathrm{L}$ of TE buffer $(10 \mathrm{mM}$ Tris $\mathrm{pH}=8,1 \mathrm{mM} \mathrm{EDTA})$ and $10 \mu \mathrm{L}$ of proteinase $\mathrm{K}(10 \mathrm{mg} / \mathrm{mL})$. Incubate at $65^{\circ} \mathrm{C}$ for $1 \mathrm{~h}$.

12. Run $20 \mu \mathrm{L}$ aliquots on a $0.6 \%$ gel to check digestion efficiency. Successful digestions show mostly fragments in the $3.0-0.5 \mathrm{~kb}$ range.

\section{Proximity ligation and crosslink reversal}

1. Incubate the Mbol-digested samples at $65^{\circ} \mathrm{C}$ in a heating block for 20 min to inactivate Mbol, then cool to RT.

2. Centrifuge the tubes for $5 \mathrm{~min}$ at $1,000 \times \mathrm{g}$ at RT, remove the supernatant, and dissolve the pellet in $200 \mu \mathrm{L}$ of fresh ligase buffer.

3. Add $1,000 \mu \mathrm{L}$ of the ligation master mix to each sample. To prepare $1,000 \mu \mathrm{L}$ of the ligation master mix, see Table 2 .

4. Mix by inverting and incubate at RT overnight with slow rotation $(9 \mathrm{rpm})$

5. Eliminate RNA and protein residues by adding $100 \mu \mathrm{L}$ of proteinase $\mathrm{K}(10 \mathrm{mg} / \mathrm{mL})$ and $10 \mu \mathrm{L}$ of RNase $\mathrm{A}(10 \mathrm{mg} / \mathrm{mL})$. Incubate samples at $55^{\circ} \mathrm{C}$ for $45-60$ min.

6. Continue incubating samples at $65^{\circ} \mathrm{C}$ for an additional $4 \mathrm{~h}$.

\section{DNA shearing and size selection}

1. Cool tubes to RT.

2. Centrifuge for $5 \mathrm{~min}$ at $1,000 \times g$ at $4{ }^{\circ} \mathrm{C}$.

3. Split the sample into three $400 \mu \mathrm{L}$ aliquots in $2 \mathrm{~mL}$ tubes and add $2 \mu \mathrm{L}$ of glycogen $(20 \mathrm{mg} / \mathrm{m}), 40 \mu \mathrm{L}$ of sodium acetate (3 M, pH = 5.2), and $2.5 x$ volumes $(1 \mathrm{~mL})$ of $100 \%$ ethanol to each tube. Mix by inverting and incubate at $-80^{\circ} \mathrm{C}$ for $45-60 \mathrm{~min}$.

4. Centrifuge at $16,000 \times g$ at $4{ }^{\circ} \mathrm{C}$ for $25 \mathrm{~min}$. Keep the tubes on ice after spinning and carefully remove the supernatant by pipetting

5. Wash the DNA pellets by resuspending in $800 \mu \mathrm{L}$ of $70 \%$ ethanol. Centrifuge at $16,000 \times g$ at $4{ }^{\circ} \mathrm{C}$ for $5 \mathrm{~min}$.

6. Remove the supernatant and perform the wash once more with $800 \mu \mathrm{L}$ of $70 \%$ ethanol.

7. Dissolve the pellet in $130 \mu \mathrm{L}$ of $1 x$ Tris buffer $(10 \mathrm{mM}$ Tris- $\mathrm{HCl}, \mathrm{pH}=8)$ and incubate at $37^{\circ} \mathrm{C}$ for 15 min to fully dissolve the DNA. If necessary, use pipetting to resuspend any precipitate.

8. Measure the DNA yield; $2.5-5 \mu \mathrm{g}$ of chromatin can be expected for $1 \times 10^{6}$ cells. Check the ligation by running $\pm 200 \mathrm{ng}$ of the $3 \mathrm{C}$ product on a $0.6 \%$ agarose gel. Successful ligations mostly show DNA fragments $>3 \mathrm{~kb}$. Store the samples at $-20^{\circ} \mathrm{C}$.

9. Dilute a sample in a $0.65 \mathrm{~mL}$ tube suitable for sonication to $10 \mathrm{ng} / \mu \mathrm{L}$ in $100 \mu \mathrm{L}$ of $1 \mathrm{x}$ Tris buffer volume (1 $\mu \mathrm{g}$ per tube). The standard amount used for library preparation is $3 \mu \mathrm{g}$, so perform the sonication in three separate tubes if necessary.

10. Shear DNA to a size of $150-700 \mathrm{bp}$ (average $=400-500 \mathrm{bp}$ ) using the following parameters on the sonicator: Cycles: $6-8$ of $20 \mathrm{~s}$ on $-60 \mathrm{~s}$ off. This should make the DNA suitable for high-throughput sequencing library preparation using Illumina sequencers.

11. Transfer the sheared DNA to a normal new safe-lock tube. Pool multiple sonications from the same sample.

12. Warm a bottle of DNA purification beads at RT. From now on, use low binding tips.

13. Add $1.8 x$ volumes of beads to the DNA tube and resuspend gently.

14. Incubate at RT for 5 min.

15. Collect the beads with a magnetic rack. Wash the beads $2 x$ with $1 \mathrm{~mL}$ of freshly prepared $80 \%$ ethanol while keeping the tubes in the magnetic rack.

NOTE: Remove all ethanol, including residual droplets.

16. Air-dry the beads briefly (2-3 min) at RT.

NOTE: Do not dry beads longer than $5 \mathrm{~min}$. This will decrease the DNA yield

17. Resuspend the beads with $90 \mu \mathrm{L}$ of $1 \mathrm{x}$ Tris buffer $(10 \mathrm{mM}$ Tris- $\mathrm{HCl}, \mathrm{pH}=8)$ to elute the DNA.

18. Measure the DNA yield and analyze a $5 \mu \mathrm{L}$ aliquot on a $1.5 \%$ gel. There should be very little loss compared to the presonication yield.

\section{Library preparation for sequencing}

1. Add $15 \mu \mathrm{L}$ of master mix from the library preparation kit. To repair the ends of sheared DNA, combine $10 \mu \mathrm{L}$ of $10 \mathrm{x}$ end repair reaction buffer and $5 \mu \mathrm{L}$ of end repair enzyme mix.

2. Incubate at RT for $30 \mathrm{~min}$

3. Add 1.1x volume of DNA purification beads and resuspend gently.

4. Incubate at RT for $5 \mathrm{~min}$.

5. Collect the beads with a magnetic rack. Wash the beads twice with $1 \mathrm{~mL}$ of freshly prepared $80 \%$ ethanol while keeping the tubes in the magnetic rack. Remove ethanol.

6. Air-dry the beads for $2-3 \mathrm{~min}$ at RT. Resuspend the beads with $42 \mu \mathrm{L}$ of $1 \mathrm{x}$ Tris buffer $(10 \mathrm{mM}$ Tris- $\mathrm{HCl}, \mathrm{pH}=8)$ to elute the DNA.

7. Add $8 \mu \mathrm{L}$ of $\mathrm{dA}$-tailing master mix to each sample. To prepare the $\mathrm{dA}$-tailing master mix, combine $5 \mu \mathrm{L}$ of $10 \mathrm{x} \mathrm{dA}$-tailing reaction buffer and 3 $\mu \mathrm{L}$ of Klenow fragment exo minus. 
8. Incubate at $37^{\circ} \mathrm{C}$ for $30 \mathrm{~min}$.

9. Add $2 \mu \mathrm{L}$ calf intestinal alkaline phosphatase (CIP) to dephosphorylate DNA.

10. Incubate for $30 \mathrm{~min}$ at $37^{\circ} \mathrm{C}$, then $60 \mathrm{~min}$ at $50^{\circ} \mathrm{C}$.

11. Add $1.1 \mathrm{x}$ volumes of DNA purification beads and resuspend gently.

12. Incubate at RT for 5 min.

13. Collect the beads with a magnetic rack. Wash the beads $2 x$ with $1 \mathrm{~mL}$ of freshly prepared $80 \%$ ethanol while keeping the tubes in the magnetic rack.

14. Air-dry the beads briefly $(2-3 \mathrm{~min})$ at RT. Resuspend beads with $35 \mu \mathrm{L}$ of $1 \mathrm{x}$ Tris buffer $(10 \mathrm{mM}$ Tris- $\mathrm{HCl}, \mathrm{pH}=8)$ to elute the DNA.

15. Perform the adapter ligation reaction. Use reduced adapter/ligase concentrations as mentioned in Table 3.

16. Incubate at $20^{\circ} \mathrm{C}$ for $15 \mathrm{~min}$.

17. Add $3 \mu \mathrm{L}$ of the mixture of uracil DNA glycosylase and DNA glycosylase lyase endonuclease VII (e.g., USER) enzyme, mix by pipetting, and incubate at $37^{\circ} \mathrm{C}$ for $15 \mathrm{~min}$.

18. Increase the volume to $100 \mu \mathrm{L}$ with water, boil $5 \mathrm{~min}$ at $96^{\circ} \mathrm{C}$, then keep samples on ice.

19. Add $1.1 \mathrm{x}$ volumes of DNA purification beads and resuspend gently.

20. Incubate at RT for 5 min.

21. Collect the beads with a magnetic rack. Wash the beads $2 x$ with $1 \mathrm{~mL}$ of freshly prepared $80 \%$ ethanol while keeping the tubes in the magnetic rack.

22. Air-dry the beads for $2-3$ min at RT. Resuspend the beads with $50 \mu \mathrm{L}$ of $1 x$ Tris buffer $(10 \mathrm{mM}$ Tris- $\mathrm{HCl}$, pH $=8)$ to elute the DNA.

\section{4C chromatin interaction library amplification and purification}

1. Amplify the $4 \mathrm{C}$ library using $10 \mu \mathrm{L}$ of library to carry out the first PCR. The PCR setup and program can be found in the Table 4 .

2. Perform nested PCR. The nested PCR setup and program can be found in the Table 5.

3. Pool PCR products for each library and purify with a $1.1 \times$ DNA purification beads.

4. Measure DNA yield and analyze a $5 \mu \mathrm{L}$ aliquot on a $1.5 \%$ gel.

5. Adjust the library concentration and sequence the library. If indexed, the libraries can be pooled prior to sequencing.

\section{Representative Results}

Six days after the induction of ESC differentiation in the hanging drops, we obtained a homogenous population of EBs that were used for further analyses (Figure 1). We adapted the UMI-4C method ${ }^{23}$ to quantify specific chromatin interaction at promoters of lineage specific genes in EBs ${ }^{24}$. A schematic overview of the protocol with representative quality control gels at different steps is shown in Figure $2 \mathrm{~A}$. The first quality control was carried out to determine the efficiency of the Mbol restriction enzyme digestion. Efficient digestion showed a fragment size of less than 3 $\mathrm{kbp}$ (Figure 2B). Of note, mESC and EB chromatin digestion was difficult and sometimes residual undigested chromatin persisted. The second quality control was carried out after ligation to verify that most of the fragments were now $>3 \mathrm{kbp}$ (Figure 2B). Then, chromatin fragments obtained after sonication were analyzed by gel electrophoresis. Fragment sizes of 400-500 bp were expected (Figure 2B).

After dephosphorylation and single-end adapter ligation, two rounds of PCR were performed to amplify the targets of interest. A nested approach was used to design a set of two primers for each locus. This helped improve specificity. Each target was amplified separately with two different primer pairs to optimize PCR conditions (i.e., primer pairs A and B for the Pou5f1 locus and primer pairs $C$ and D for the $T$ locus, respectively) and resulted in a DNA smear around 400 bp (Figure 2C). Alternatively, multiplex PCR was performed to amplify targets A and C simultaneously (Figure 2D) and resulted in a similar fragment size after purification (Figure 2D). Primers used for 4C library preparation (loci of Pou5f1 and $T$ ) can be found in Table 6 .

For data analysis, raw sequencing reads were first aligned against the refence mm10 mouse genome, were all duplicated, and low quality (< 20) reads were removed. For each bait, the information on each restriction fragment was obtained by computing the number of read fragments, and a raw contact profile was obtained. Next, the region of interest was defined as all restriction fragments with $2 \mathrm{kbp}$ and $250 \mathrm{kbp}$ distance to the bait. The size of each restriction fragment was increased by aggregating the adjacent restriction fragments sequentially to smoothen the profiles until a threshold of $5 \%$ of the total number of raw contacts was reached in the region of interest. To ensure that the replicates were integrated, and conditions were compared, we included both slopes and random intercepts on the restriction fragment level. The average profile per condition and the fold change between them were plotted as shown in Figure 3. During EB differentiation, the contacts between the enhancers and the promoter of the pluripotency gene Pou5f1 decreased, while enhancer-promoter contacts of mesendoderm lineage instructive transcription factor $T$ increased (Figure 3), providing functional insights about these developmental enhancers. 


\section{D0 mESCs}

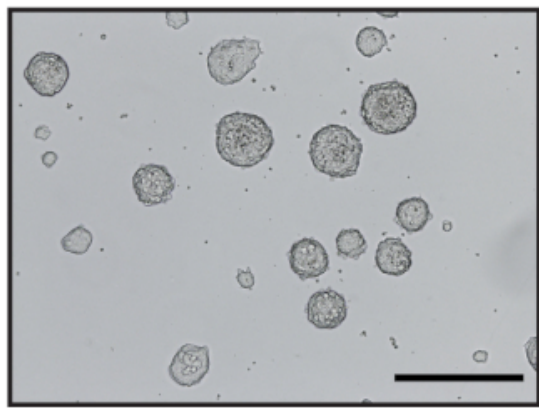

D6 EBs

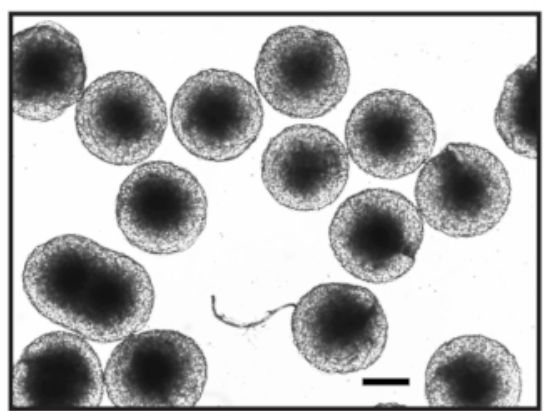

Figure 1: Representative images of mESC and derived embryoid bodies. Day $0 \mathrm{mESC}$ cultured in serum-free conditions (left) and homogenous day 6 EBs (right) observed by an inverted microscope. Scale Bar $=500 \mu \mathrm{m}$. Please click here to view a larger version of this figure.

A
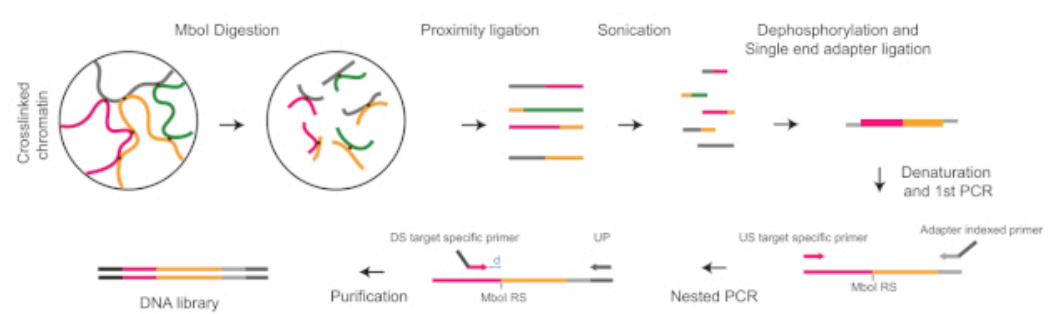

B

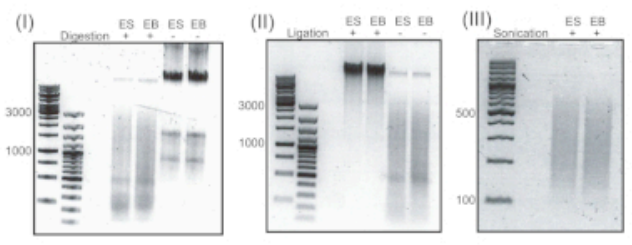

C

D
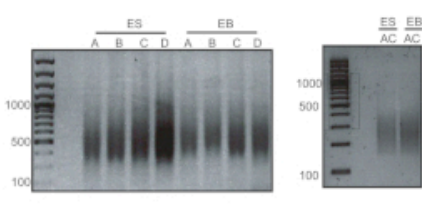

Figure 2: 4C workflow and representative images of the main steps of the protocol. (A) Schematic workflow of the quantitative $4 \mathrm{C}$. RS = restriction site; US = upstream; DS = downstream; UP = universal primer; $\mathrm{D}=$ the distance between RS and DS should ideally be 5-15 bp. (B) Examples of Mbol-digested chromatin (I), in-nuclei ligated chromatin (II), and sonicated chromatin (III). The numbers on the left indicate the DNA sizes determined by the DNA ladder run for each sample. (C) Examples of PCR amplification at the two loci: Pou5f1 (primers A and B) and $T$ (primer C and D). (D) Examples of multiplex PCR amplification at Pou5f1 and $T$ loci using primers A and C. ES = embryonic stem cells; EB = embryoid bodies. Please click here to view a larger version of this figure.
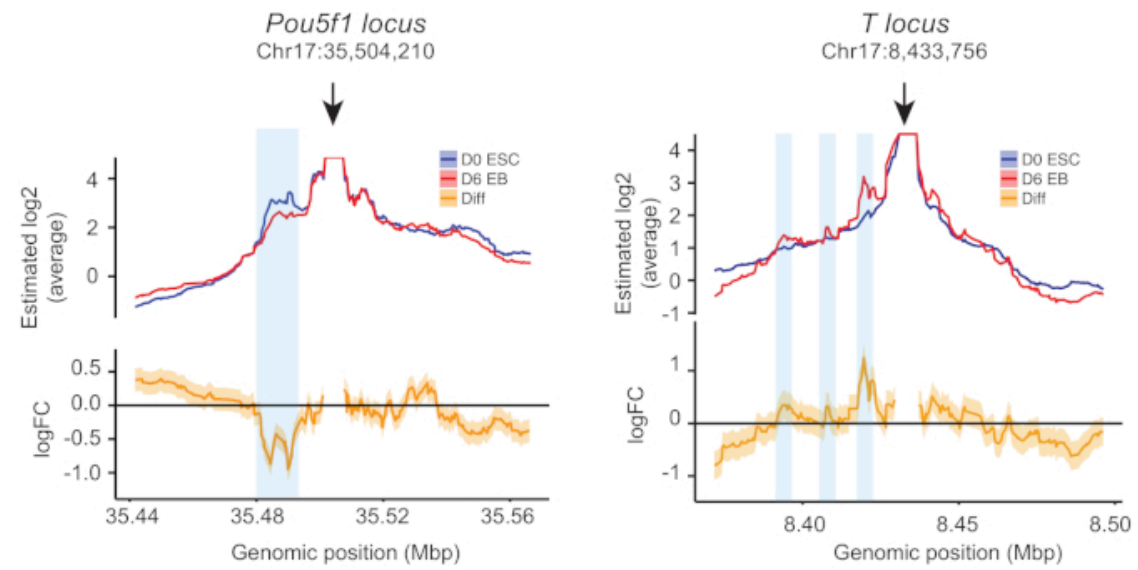

Figure 3: Examples of $4 \mathrm{C}$ profiles. Quantitative $4 \mathrm{C}$ profiles for baits located on the Pou5f1 and $T$ gene promoters assayed in mESCs and Day 6 EBS. The top panel shows plots of average contacts generated from two independent biological replicates; the bottom panel shows the average contact fold change of Day 6 EBs versus mESCs (average of the two replicates). Light blue boxes indicate the location of enhancers with dynamic changes during differentiation. Figure adapted from Tian et al. ${ }^{24}$. Please click here to view a larger version of this figure. 


\begin{tabular}{|l|l|}
\hline & For $5 \mathrm{~mL}$ \\
\hline $1 \mathrm{M}$ Tris-HCl, pH8.0 & $50 \mu \mathrm{L}$ \\
\hline $5 \mathrm{M} \mathrm{NaCl}$ & $10 \mu \mathrm{L}$ \\
\hline $10 \%$ Igepal CA630 & $100 \mu \mathrm{L}$ \\
\hline $50 x$ Roche complete protease inhibitors & $100 \mu \mathrm{L}$ \\
\hline MilliQ Water & $4.74 \mathrm{~mL}$ \\
\hline
\end{tabular}

Table 1: Lysis buffer.

\begin{tabular}{|l|l|}
\hline & For $1000 \mu \mathrm{L}$ \\
\hline MilliQ Water & $869 \mu \mathrm{L}$ \\
\hline $10 X$ NEB T4 DNA Ligase Buffer & $120 \mu \mathrm{L}$ \\
\hline $20 \mathrm{mg} / \mathrm{mL}$ Bovine Serum Albumin & $6 \mu \mathrm{L}$ \\
\hline $2000 \mathrm{U} / \mu \mathrm{L}$ T4 DNA Ligase & $5 \mu \mathrm{L}$ \\
\hline
\end{tabular}

Table 2: Ligation master mix preparation.

\begin{tabular}{|l|l|}
\hline & For $15 \mu \mathrm{L}$ \\
\hline 5X Quick Ligation Reaction Buffer & $10 \mu \mathrm{L}$ \\
\hline NEBNext Adaptor & $3 \mu \mathrm{L}$ \\
\hline Quick T4 DNA ligase & $2 \mu \mathrm{L}$ \\
\hline
\end{tabular}

\section{Table 3: Adapter ligation reaction.}

\begin{tabular}{|c|c|}
\hline PCR setup & \\
\hline Adaptor ligated library-on-deads & $10 \mu \mathrm{L}$ \\
\hline PCR grade water & $20.25 \mu \mathrm{L}$ \\
\hline $10 \mu \mathrm{M}$ Target specific primer & $3.75 \mu \mathrm{L}$ \\
\hline $10 \mu \mathrm{M}$ NEB Index primer & $3.75 \mu \mathrm{L}$ \\
\hline Herculase II 5X buffer & $10 \mu \mathrm{L}$ \\
\hline $10 \mathrm{Mm}$ dNTPs & $1.25 \mu \mathrm{L}$ \\
\hline Herculase II polymerase & $1 \mu \mathrm{L}$ \\
\hline Total volume & $50 \mu \mathrm{L}$ \\
\hline \multicolumn{2}{|l|}{ PCR program } \\
\hline \multicolumn{2}{|l|}{ Step 1: $98^{\circ} \mathrm{C}-2 \mathrm{~min}$} \\
\hline \multicolumn{2}{|l|}{ Step 2: $98^{\circ} \mathrm{C}-20 \mathrm{~s}$} \\
\hline \multicolumn{2}{|l|}{ Step 3: $65^{\circ} \mathrm{C}-30 \mathrm{~s}$} \\
\hline \multicolumn{2}{|l|}{ Step 4: $72{ }^{\circ} \mathrm{C}-45 \mathrm{~s}$} \\
\hline \multicolumn{2}{|c|}{ Step 5: go to step 2 to make a total of $15-18$ cycles } \\
\hline \multicolumn{2}{|l|}{ Step 6: $72{ }^{\circ} \mathrm{C}-3 \mathrm{~min}$} \\
\hline Step 7: $4{ }^{\circ} \mathrm{C}-$ hold & \\
\hline
\end{tabular}

Table 4: 4C chromatin interaction library amplification, first PCR. 


\begin{tabular}{|c|c|}
\hline Nested PCR setup & \\
\hline DNA fragment from the first PCR & $10 \mu \mathrm{L}$ \\
\hline PCR grade water & $20.25 \mu \mathrm{L}$ \\
\hline $10 \mu \mathrm{M}$ specific primer+P5 Illumina primer & $3.75 \mu \mathrm{L}$ \\
\hline $10 \mu \mathrm{M}$ P7 Illumina primer & $3.75 \mu \mathrm{L}$ \\
\hline Herculase II 5X buffer & $10 \mu \mathrm{L}$ \\
\hline $10 \mathrm{Mm}$ dNTPs & $1.25 \mu \mathrm{L}$ \\
\hline Herculase II polymerase & $1 \mu \mathrm{L}$ \\
\hline Total volume & $50 \mu \mathrm{L}$ \\
\hline \multicolumn{2}{|l|}{ Nested PCR program } \\
\hline \multicolumn{2}{|l|}{ Step 1: $98{ }^{\circ} \mathrm{C}-2 \mathrm{~min}$} \\
\hline \multicolumn{2}{|l|}{ Step 2: $98^{\circ} \mathrm{C}-20 \mathrm{~s}$} \\
\hline \multicolumn{2}{|l|}{ Step 3: $65^{\circ} \mathrm{C}-30 \mathrm{~s}$} \\
\hline \multicolumn{2}{|l|}{ Step 4: $72{ }^{\circ} \mathrm{C}-45 \mathrm{~s}$} \\
\hline \multicolumn{2}{|l|}{ Step 5: go to step 2 to make a total of $15-18$ cycles } \\
\hline \multicolumn{2}{|l|}{ Step 6: $72{ }^{\circ} \mathrm{C}-3 \mathrm{~min}$} \\
\hline Step 7: $4{ }^{\circ} \mathrm{C}-$ hold & \\
\hline
\end{tabular}

Table 5: 4C chromatin interaction library amplification, nested PCR.

\begin{tabular}{|c|c|}
\hline Name & Sequence (5'-3') \\
\hline DS-Oct4-A & $\begin{array}{l}\text { AATGATACGGCGACCACCGAGATCTACACTCTTTCCCTACACGACG } \\
\text { CTCTTCCGATCTTCTTGCAAAGATAACTAAGCACCAGGCCAG }\end{array}$ \\
\hline US-Oct4-A & TCTCTTGCAAAGATAACTAAGCACCAGGCC \\
\hline DS-Oct4-B & $\begin{array}{l}\text { AATGATACGGCGACCACCGAGATCTACACTCTTTCCCTACACGACG } \\
\text { CTCTTCCGATCTGTGATGGGTCAGCAGGGCTGGAGCCGGGCT }\end{array}$ \\
\hline US-Oct4-B & ACCAGGTGGGGGTGATGGGTCAGCAGGGCT \\
\hline DS-T-C & $\begin{array}{l}\text { AATGATACGGCGACCACCGAGATCTACACTCTTTCCCTACACGACG } \\
\text { CTCTTCCGATCTCCTGGGTCCCTGCACATTCGCCAAAGGAGC }\end{array}$ \\
\hline US-T-C & GATTACACCTGGGTCCCTGCACATTCGCCAA \\
\hline DS-T-D & $\begin{array}{l}\text { AATGATACGGCGACCACCGAGATCTACACTCTTTCCCTACACGACG } \\
\text { CTCTTCCGATCTGGCTTTGGAGAGGTCAAGGAGACCCGGGAG }\end{array}$ \\
\hline US-T-D & GCTGAGGCTTTGGAGAGGTCAAGGAGACC \\
\hline UP-4C & CAAGCAGAAGACGGCATACGA \\
\hline Adap-i1 & $\begin{array}{l}\text { CAAGCAGAAGACGGCATACGAGATCGTGATGTGACTGGAGTTCAGA } \\
\text { CGTGTGCTCTTCCGATC }\end{array}$ \\
\hline Adap-i2 & $\begin{array}{l}\text { CAAGCAGAAGACGGCATACGAGATACATCGGTGACTGGAGTTCAGA } \\
\text { CGTGTGCTCTTCCGATC }\end{array}$ \\
\hline Adap-i3 & $\begin{array}{l}\text { CAAGCAGAAGACGGCATACGAGATGCCTAAGTGACTGGAGTTCAGA } \\
\text { CGTGTGCTCTTCCGATC }\end{array}$ \\
\hline Adap-i4 & $\begin{array}{l}\text { CAAGCAGAAGACGGCATACGAGATTGGTCAGTGACTGGAGTTCAGA } \\
\text { CGTGTGCTCTTCCGATC }\end{array}$ \\
\hline
\end{tabular}

Table 6: Primers used for $4 \mathrm{C}$ library preparation.

\section{Discussion}

The hanging drop culture method does not need additional growth factors or cytokines and reproducibly generates homogeneous populations of EBs from a predetermined number of $\mathrm{mESCs}^{5}$. Here we describe a protocol of quantitative $4 \mathrm{C}$ adapted from the UMI-4C approach to quantify enhancer-promoter contact of lineage specific transcription factors in the EB differentiation model. We identified chromatin regions that contact promoters of Pou5f1 and $T$ genes in a dynamic fashion during EB differentiation. Pou5f1 was downregulated during EB differentiation and the contact frequency between the Pou5f1 promoter and its distal enhancer decreased. Conversely, T was upregulated during EB differentiation and we identified three enhancers for which contact frequencies with their promoter are decreased (Figure 3). To confirm the identification, a 
chromatin immunoprecipitation (ChIP) assay of active histone mark H3K27ac can be performed ${ }^{24}$, as this histone mark has been shown to be associated with enhancer activation and enhancers lose this mark during their inactivation ${ }^{11}$.

A standard $4 \mathrm{C}$ technique has been extensively used to survey the chromatin contact profile of specific genomic sites ${ }^{25}$. However, this approach is difficult to interpret quantitatively even after extensive normalization ${ }^{26,27,28}$ because of the biases introduced by the heterogeneity of PCR fragment size and the impossibility to distinguish PCR duplicates. Our quantitative $4 \mathrm{C}$ method is largely identical to the UMI-4C technique that allows the quantification of single molecules using sonication and a nested-ligation-mediated PCR step to bypass the limitation of the classic $4 \mathrm{C}$ approach $^{23}$. However, unlike the UMI-4C that uses unique molecular identifiers, our quantitative $4 \mathrm{C}$ protocol allows the quantification of single molecules based on the specific DNA break produced by the sonication step. It makes our protocol compatible with commercial DNA library preparation kits, obviating the need of primers with unique molecular identifiers.

Our protocol involves several key steps that should be considered. As in the classical $4 \mathrm{C}$ method ${ }^{28}$, critical factors of our protocol are the efficiency of the digestion and the ligation during the preparation of the $3 \mathrm{C}$ molecules. Low digestion/ligation efficiencies can dramatically decrease the complexity of interaction with a fragment of interest, resulting in a reduced resolution. As previously described ${ }^{23}$, another critical step of the protocol is the design of the primers for the library amplification. The second PCR reaction primers should be located 5-15 nt from the interrogated restriction site. In a $75 \mathrm{nt}$ sequencing read, this allows for at least $40 \mathrm{nt}$ left of the capture length for mapping. The primer used in the first PCR reaction should be designed upstream of the second primer with no overlap and both should be specific enough to ensure efficient DNA amplification. For multiplexing, primers should be designed independently, aiming for a melting temperature $\left(T_{m}\right)$ of $60-65^{\circ} \mathrm{C}$. Moreover, as for other $3 \mathrm{C}$ techniques, the resolution of the quantitative $4 \mathrm{C}$ method is determined by the restriction enzyme used in the protocol ${ }^{25}$. This protocol uses a restriction enzyme with a $4 \mathrm{bp}$ recognition site, Mbol. The maximum resolution with this enzyme is around $500 \mathrm{bp}$, but this is highly locus dependent and rarely achieved. Another limitation is that interactions that occur between elements located in the same restriction fragment are not detectable. In addition, interactions occurring at a distance of one restriction site cannot be distinguished from the undigested background. The use of a fill-in step prior to ligation might allow the detection of these interactions.

Quantitative 4C is ideally suited to interrogate chromatin contacts of targeted loci. However, the specific PCR amplification step limits the number of loci that can be investigated simultaneously. A way to increase the number of targeted loci is to multiplex the PCR steps to simultaneously amplify several targets, but this requires compatibility of the primers used and testing each primer pair prior to implementation. If global changes of chromatin architecture at promoters are desired, genome-wide approaches such as $\mathrm{Hi}-\mathrm{C}, \mathrm{PC} \mathrm{Hi}-\mathrm{C}$, or $\mathrm{HiChIP}$ would be more appropriate $29,30,31$.

\section{Disclosures}

The authors have nothing to disclose.

\section{Acknowledgments}

We would like to thank F. Le Dily, R. Stadhouders and members of the Graf laboratory for their advice and discussions. G.S. was supported by a Marie Sklodowska-Curie fellowship (H2020-MSCA-IF-2016, miRStem), T.V.T by a Juan de la Cierva postdoctoral fellowship (MINECO, FJCl-2014-22946). This work was supported by the European Research Council under the $7^{\text {th }}$ Framework Programme FP7 (ERC Synergy Grant 4D-Genome, grant agreement 609989 to T.G.), the Spanish Ministry of Economy, Industry and Competitiveness (MEIC) to the EMBL partnership, Centro de Excelencia Severo Ochoa 2013-2017 and CERCA Program Generalitat de Catalunya.

\section{References}

1. Evans, M. J., Kaufman, M. H. Establishment in culture of pluripotential cells from mouse embryos. Nature. 292 (5819), 154-156 (1981).

2. Martello, G., Smith, A. The nature of embryonic stem cells. Annual Review Cell and Developmental Biology. 30, 647-675 (2014).

3. Martin, G. R. Isolation of a pluripotent cell line from early mouse embryos cultured in medium conditioned by teratocarcinoma stem cells. Proceedings of the National Academy of Science U. S. A. 78 (12), 7634-7638 (1981).

4. Loh, K. M., Lim, B., Ang, L. T. Ex uno plures: molecular designs for embryonic pluripotency. Physiological Reviews. 95 (1), $245-295$ (2015).

5. Sheridan, S. D., Surampudi, V., Rao, R. R. Analysis of embryoid bodies derived from human induced pluripotent stem cells as a means to assess pluripotency. Stem Cells International. 2012, 738910 (2012).

6. Gaszner, M., Felsenfeld, G. Insulators: exploiting transcriptional and epigenetic mechanisms. Nature Reviews in Genetics. 7 (9), $703-713$ (2006).

7. Lenhard, B., Sandelin, A., Carninci, P. Metazoan promoters: emerging characteristics and insights into transcriptional regulation. Nature Reviews in Genetics. 13 (4), 233-245 (2012).

8. Long, H. K., Prescott, S. L., Wysocka, J. Ever-Changing Landscapes: Transcriptional Enhancers in Development and Evolution. Cell. 167 (5), 1170-1187 (2016).

9. Schoenfelder, S., Fraser, P. Long-range enhancer-promoter contacts in gene expression control. Nature Reviews in Genetics. 20 (8), $437-455$ (2019).

10. Spitz, F., Furlong, E. E. Transcription factors: from enhancer binding to developmental control. Nature Reviews in Genetics. 13 (9), $613-626$ (2012).

11. Creyghton, M. P. et al. Histone $\mathrm{H} 3 \mathrm{~K} 27$ ac separates active from poised enhancers and predicts developmental state. Proceedings of the National Academy of Sciences U. S. A. 107 (50), 21931-21936 (2010).

12. Heintzman, N. D. et al. Histone modifications at human enhancers reflect global cell-type-specific gene expression. Nature. 459 (7243), 108-112 (2009).

13. Klemm, S. L., Shipony, Z., Greenleaf, W. J. Chromatin accessibility and the regulatory epigenome. Nature Reviews in Genetics. 20 (4), 207-220 (2019). 
14. Rada-Iglesias, A. et al. A unique chromatin signature uncovers early developmental enhancers in humans. Nature. 470 (7333), $279-283$ (2011).

15. Lettice, L. A. et al. Development of five digits is controlled by a bipartite long-range cis-regulator. Development. 141 (8), 1715-1725 (2014).

16. Dekker, J., Rippe, K., Dekker, M., Kleckner, N. Capturing chromosome conformation. Science. 295 (5558), 1306-1311 (2002).

17. de Wit, E., de Laat, W. A decade of 3C technologies: insights into nuclear organization. Genes and Development. 26 (1), 11-24 (2012).

18. Lieberman-Aiden, E. et al. Comprehensive mapping of long-range interactions reveals folding principles of the human genome. Science. 326 (5950), 289-293 (2009).

19. Simonis, M. et al. Nuclear organization of active and inactive chromatin domains uncovered by chromosome conformation capture-on-chip (4C). Nature Genetics. 38 (11), 1348-1354 (2006).

20. Splinter, E., de Wit, E., van de Werken, H. J., Klous, P., de Laat, W. Determining long-range chromatin interactions for selected genomic sites using 4C-seq technology: from fixation to computation. Methods. 58 (3), 221-230 (2012).

21. Stadhouders, R. et al. Multiplexed chromosome conformation capture sequencing for rapid genome-scale high-resolution detection of longrange chromatin interactions. Nature Protocols. 8 (3), 509-524 (2013).

22. van de Werken, H. J. et al. Robust 4C-seq data analysis to screen for regulatory DNA interactions. Nature Methods. 9 (10), $969-972$ (2012).

23. Schwartzman, O. et al. UMI-4C for quantitative and targeted chromosomal contact profiling. Nature Methods. 13 (8), 685-691 (2016).

24. Tian, T. V. et al. Whsc1 links pluripotency exit with mesendoderm specification. Nature Cell Biology. 21 (7), 824-834 (2019).

25. Chen, H. et al. Dynamic interplay between enhancer-promoter topology and gene activity. Nature Genetics. 50 (9), 1296-1303 (2018).

26. Apostolou, E. et al. Genome-wide chromatin interactions of the Nanog locus in pluripotency, differentiation, and reprogramming. Cell Stem Cell. 12 (6), 699-712 (2013).

27. de Wit, E. et al. The pluripotent genome in three dimensions is shaped around pluripotency factors. Nature. 501 (7466), 227-231 (2013).

28. Krijger, P. H. L., Geeven, G., Bianchi, V., Hilvering, C. R. E., de Laat, W. 4C-seq from beginning to end: A detailed protocol for sample preparation and data analysis. Methods. 26 July (2019).

29. Mumbach, M. R. et al. HiChIP: efficient and sensitive analysis of protein-directed genome architecture. Nature Methods. 13 (11), $919-922$ (2016).

30. Rao, S. S. et al. A 3D map of the human genome at kilobase resolution reveals principles of chromatin looping. Cell. 159 (7), 1665-1680 (2014).

31. Schoenfelder, S., Javierre, B. M., Furlan-Magaril, M., Wingett, S. W., Fraser, P. Promoter Capture Hi-C: High-resolution, Genome-wide Profiling of Promoter Interactions. Journal of Visualized Experiments. (136), e57320 (2018). 